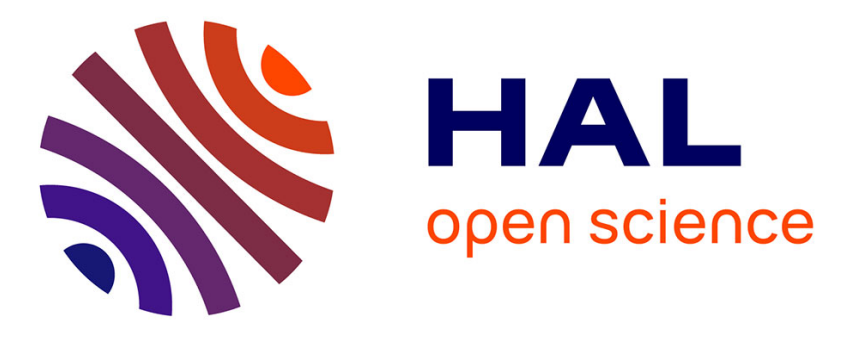

\title{
Influence of recycled coarse aggregates on permeability of fresh concrete
}

Jean-Claude Souche, Philippe Devillers, Marie Salgues, Eric Garcia-Diaz

\section{To cite this version:}

Jean-Claude Souche, Philippe Devillers, Marie Salgues, Eric Garcia-Diaz. Influence of recycled coarse aggregates on permeability of fresh concrete. Cement and Concrete Composites, 2017, 83, pp.394-404. 10.1016/j.cemconcomp.2017.08.002 . hal-01665835

\section{HAL Id: hal-01665835 \\ https://hal-imt.archives-ouvertes.fr/hal-01665835}

Submitted on 17 Dec 2017

HAL is a multi-disciplinary open access archive for the deposit and dissemination of scientific research documents, whether they are published or not. The documents may come from teaching and research institutions in France or abroad, or from public or private research centers.
L'archive ouverte pluridisciplinaire HAL, est destinée au dépôt et à la diffusion de documents scientifiques de niveau recherche, publiés ou non, émanant des établissements d'enseignement et de recherche français ou étrangers, des laboratoires publics ou privés. 


\section{INFLUENCE OF RECYCLED COARSE AGGREGATES ON PERMEABILITY OF FRESH CONCRETE}

Jean-Claude Souche

Centre des Matériaux des Mines d'Alès, Ecole des Mines d'Alès,

6 avenue de Clavières 30319 Alès cedex, France.

Jean-Claude.Souche@mines-ales.fr

Philippe Devillers

Ecole Nationale Supérieure d'Architecture de Montpellier, 179 rue de l'Espérou 34093 Montpellier cedex 5, France.

Philippe.Devillers@montpellier.archi.fr

\section{Marie Salgues}

Centre des Matériaux des Mines d'Alès, Ecole des Mines d'Alès, 6 avenue de Clavières 30319 Alès cedex, France.

Marie.Salgues@mines-ales.fr

Eric Garcia Diaz

Centre des Matériaux des Mines d'Alès, Ecole des Mines d'Alès, 6 avenue de Clavières 30319 Alès cedex, France.

Eric.Garcia-Diaz@mines-ales.fr

Summary: The following work is an experimental study of the behaviour of very early-age concrete. Six different concretes, four of them containing recycled coarse aggregates were studied for the first 2.5 hours. The studies were carried out in a ventilated tunnel in order to imitate severe desiccation conditions. In order to indirectly obtain the permeability coefficient, settlement, capillary depression and evaporation were measured for all six concretes. The initial permeability coefficient of each concrete is determined starting from initial bleeding rate. The use of recycled coarse aggregates leads to a high bleeding rate for high water to cement ratios. Permeability coefficients at air entry are then determined starting from capillary depression gradients. Recycled coarse aggregates do not seem to influence the air entry value which is highly dependent on the paste quality. At air entry, the permeability coefficient of recycled coarse aggregates concrete mixes is higher than that of natural aggregates concrete mixes. At high evaporation rates, in severe desiccation conditions, recycled coarse aggregates seem to reduce bleeding for mixture with low water cement ratios. Permeability coefficient is a key physical parameter to understand drying of fresh concrete.

Keywords: evaporation rate; capillary depression; bleeding; permeability; air entry.

"This is an Accepted Manuscript of an article published by Cement and Concrete composite - volume 83 on Oct 2017 available online:

https://doi.org/10.1016/j.cemconcomp.2017.08.002"

\section{INTRODUCTION}

The life of concrete starts when concrete components come into contact with water in the mixer. Immediately after placement, gravitational forces and the environment begin to influence the microstructure of concrete. Fresh concrete is a humid granular mixture made up of different sized particles. As the solid particles 
settle and a corresponding volume of water rises the top of the specimen, a microstructural gradient will be established throughout the thickness of concrete [1]. Settlement and bleeding strongly depend on fresh concrete permeability [2], [3]. The homogeneity of concrete is thus directly linked to the ability of water to move through the solid particles. Permeability is a key parameter to understand the hydro-mechanical behaviour of fresh concrete. High bleeding rate will be observed for concrete mixes with high water to cement ratios, low cement contents, coarsely ground cement or poorly graded aggregates.

One of the major problems with the use of recycled aggregates in structural concrete is their high water absorption capacity which leads to difficulties in controlling the properties of fresh and hardened concrete [4]. Poon et al. [5] reported that in the case of using recycled aggregates in the saturated surfacedried (SSD) state, the high water content inside the aggregate particles may result in bleeding during casting. The concrete technology unit of the University of Dundee showed that the use of recycled aggregate as a partial replacement of natural aggregate leads to a high degree of bleeding.

The situation will become further complicated when the evaporation rate is higher than the bleeding rate or once steady bleed water at the concrete surface is evaporated. Menisci will be created between the particles at the concrete surface, creating a capillary tension in the water [6], [7]. In the literature, plastic shrinkage is often attributed to capillary tension [6], [8]. According to the Young-Laplace equation, the maximum capillary tension which develops during drying is proportional to the surface tension of the pore fluid and inversely proportional to the radius of the pores being emptied. This relationship has been used to illustrate why finer cements and mixtures containing silica fumes are more susceptible to plastic shrinkage cracking [9], [10]. To insure a constant mass flow at the surface, water pressure has to decrease, which leads to the development of capillary depression. The gradients of water pressure or capillary depression as well as their evolution are connected to the ease with which water can pass through the medium, that is, with the permeability of fresh concrete [11], [12].

The aim of this paper is to investigate the influence of recycled coarse aggregates on fresh concrete permeability. An experimental study of the behaviour of concretes at very early-age was carried out. Six concretes mixes were studied, four of them with recycled coarse aggregates. In order to determine permeability coefficients and their evolution, settlement, horizontal deformations, capillary depression and evaporation rate were simultaneously measured for the six concretes. The tests were performed in a custom-made ventilated tunnel in order to apply a constant wind speed throughout the test, while maintaining constant temperature and hygrometry. A new method to determine the air entry value has been provided, starting from capillary pressure gradients measurements. Direct permeability coefficient measurements are difficult to develop because fresh concrete does not exhibit a stable porous network when it is submitted to pressure gradients or water flows [13], [14]. Owing to the low accuracy of permeability measurement, this paper presents a new method to determine, indirectly, the permeability coefficient. The few papers dedicated to the permeability of fresh concrete focus on the identification of permeability coefficient starting from the initial constant bleeding rate [2], [13], [15], [16]. This paper is the first to propose an identification of permeability coefficient after bleeding slowed down and stopped by measuring the gradient of pore water pressure controlled both by permeability and bulk modulus. 


\section{MATERIALS AND METHODS}

\subsection{Mix proportion of the six concretes}

Table 1: properties of aggregates

\begin{tabular}{cccc}
\hline type & nominal size & density $\left(\mathrm{kg} / \mathrm{m}^{3}\right)$ & water absorption $(\%)$ \\
\hline crushed & $4 / 10$ & 2710 & 0.62 \\
calcareous & $6.3 / 20$ & 2710 & 0.57 \\
recycled & $4 / 10$ & 2290 & 5.60 \\
coarse & $10 / 20$ & 2260 & 5.80 \\
aggregates & $0 / 4$ & 2550 & 1.00 \\
sand & & & \\
\hline
\end{tabular}

Table 2: mix design of concretes $\left(\mathrm{kg} / \mathrm{m}^{3}\right)$

\begin{tabular}{lcccccc}
\hline & $\mathrm{BR}_{0.60}$ & $\mathrm{BN}_{0.59}$ & $\mathrm{BR}_{0.52}$ & $\mathrm{GcR}_{0.45}$ & $\mathrm{GcN}_{0.45}$ & $\mathrm{GcR}_{0.38}$ \\
\hline cement & 282 & 272 & 286 & 339 & 303 & 345 \\
superplaticizer & 1.358 & 1.399 & 1.419 & 2.201 & 2.128 & 2.238 \\
calcareous filler & 31 & 45 & 31 & 54 & 59 & 54 \\
$\begin{array}{l}\text { crushed calcareous } \\
6.3 / 20\end{array}$ & - & 825 & - & - & 821 & - \\
$\begin{array}{l}\text { crushed calcareous } \\
4 / 10\end{array}$ & - & 268 & - & - & 268 & - \\
sand 0/4 & 806 & 785 & 817 & 790 & 781 & 803 \\
recycled aggregate & 701 & - & 710 & 689 & - & 700 \\
$\begin{array}{l}10 / 20 \\
\text { recycled aggregate }\end{array}$ & 163 & - & 165 & 160 & - & 162 \\
$4 / 10$ & 232 & 181 & 210 & 215 & 167 & 194 \\
water & 1.8 & 0.9 & 2.9 & 1.9 & 1.0 & 2.7 \\
air entrapped (\%) & 0.60 & 0.59 & 0.52 & 0.45 & 0.45 & 0.38 \\
Weff/cm & & & & & & \\
\hline
\end{tabular}

A blended hydraulic cement CEM II/A-L $42.5 \mathrm{~N}$ was used for the entire experimental process. Calcareous filler was also used to improve the compacity of the granular skeleton of concrete if necessary. The two coarse aggregates used were of a calcareous type, crushed gravel $(4 / 10 \mathrm{~mm}$ and $6.3 / 20 \mathrm{~mm})$. The fine aggregate used was a half crushed washed sand $(0 / 4 \mathrm{~mm})$. Two recycled coarse aggregates $(4 / 10 \mathrm{~mm}$ and $10 / 20 \mathrm{~mm})$ were also used in order to study the effect of recycled coarse aggregates on fresh concrete properties (Table 1). Fig. 1 gives the size grading curves of all coarse aggregates. High water-reducing superplasticizer was also used. The effective water $\left(\mathrm{w}_{\text {eff }}\right)$ is defined as the difference between the total water (w) and the water absorbed by the aggregates. Recycled aggregates 
were supposed to be saturated at nominal absorption, dried in surface (SSD State). The pre-saturation water corresponds to the amount of water in the aggregates before mixing. If aggregates are oversaturated, the extra water absorption in aggregates is taken into account in the effective water. Cementitious material $(\mathrm{cm})$ takes into account all the cement and a quarter of the calcareous filler. Table 2 gives the mixture proportions of the six concretes investigated. The mixes have been designed for the French national project RECYBETON using the software BétonlabPro 3. The mixes were established to target a compressive strength of 32 $\mathrm{MPa}$ for building concretes and $40 \mathrm{MPa}$ for civil engineering concretes. Granular coefficient of recycled coarse aggregates (5.17) is lower than that of natural coarse aggregates (5.76) [17]. Thus to target the same compressive strength, we need to increase the binder quantity, while maintaining the same workability. A workability criterion was selected for the six concretes: a slump of $20 \pm 3 \mathrm{~cm}$ from the Abrams cone test. The concrete was placed in the moulds by means of vibration.

The life of concrete starts when the concrete components come into contact with water. Fresh concrete is a system of particles with empty spaces between them filled with water or air or a combination of both. The beginning point will then be taken as the point when water and cement come into contact with each other in the mixer.

\subsection{Experimental set-up}

\subsubsection{Environmental conditions during tests}

The tests were carried out over 2.5 hours in a ventilated tunnel (Fig. 2) of crosssection $0.6 \mathrm{mx} 0.15 \mathrm{~m}$ and length of $3 \mathrm{~m}$, enabling a wind speed of $7.5 \pm 0,5 \mathrm{~m} \cdot \mathrm{s}^{-1}$ to be applied. The tunnel was placed in an air conditioned room with regulated temperature $\left(\mathrm{T}=21^{\circ} \mathrm{C} \pm 2^{\circ} \mathrm{C}\right)$ and hygrometry $(\mathrm{RH}=53 \% \pm 4 \%)$. The calibration of this ventilated tunnel consisted of measuring the wind speed in various locations for various fan rotation speeds. The results of these calibration tests showed a very low wind speed gradient [18].

The ventilated tunnel provides a uniform air circulation throughout the chamber, during the test, with no disturbance of air flow. An anemometer placed downstream was used to check the wind speed in the tunnel and a hygrometer was placed upstream to check the relative humidity and temperature inside the tunnel. The air circulates in an open circuit to avoid any temperature increase in the tunnel. Closed circuit tests carried out during the development of the tunnel had shown that it was impossible to ensure a temperature of $21^{\circ} \mathrm{C}$ throughout the test. It takes about 35 minutes to cast concrete in the moulds and to place them in the ventilated tunnel. On average, therefore, the tests start 35 minutes after the water and cement come into contact.

\subsubsection{Measurement of settlement and capillary depression}

The measurement of vertical deformation took place in a prismatic metal mould with dimensions of $30 \mathrm{~cm} \times 30 \mathrm{~cm} \times 8.2 \mathrm{~cm}$, whose walls were coated by Teflon (Fig. 3). The concrete was put in place using a plastic sheet. The space between the walls of the mould and the plastic sheet was sprinkled with talc to minimise friction. Once concrete was put in place, a $2.5 \mathrm{~cm}^{2}$ steel plate is placed above the concrete surface [19]. The steel plate remains on the surface of concrete despite any bleeding [20]. Penetration of the plate as well as floating of the plate is 
prevented. The reported movement of the plate at the height of the sample, recorded using a laser sensor (accuracy: $2 \mathrm{~mm} / \mathrm{Volt}$ ), gives us the settlement expressed in $\mu \mathrm{m}$. In this way, the settlement may be directly measured at the surface of the superficial particles.

Capillary depression was measured using a previously saturated porous ceramic plate, embedded in the concrete (Fig. 3). This porous ceramic plate was connected to a pressure sensor by means of a capillary tube. Measurement ends when the porous ceramic plate comes into contact with the gas phase; a bubble of air passing through the tube towards the sensor. After this point measurement is no longer possible. Evolution of the capillary depression was measured at a depth of $20 \mathrm{~mm}$ and $42 \mathrm{~mm}$ from surface.

\section{RESULTS}

\subsection{Evaporation}

The amount of evaporation from fresh concrete is controlled by environmental factors such as wind speed, temperature and relative humidity. The rate of evaporation can be estimated knowing these environmental factors and using various prediction tools, such as the formula proposed by Uno [21]:

$E\left(\mathrm{~kg} / \mathrm{m}^{2} /\right.$ hour $)=5\left(\left[T_{c}+18\right]^{2.5}-R H\left[T_{a}+18\right]^{2.5}\right)(V+4) 10^{-6}$

Where $\mathrm{E}$ is the evaporation rate, $\mathrm{T}_{\mathrm{c}}$ the concrete temperature, $\mathrm{T}_{\mathrm{a}}$ the air temperature, $\mathrm{RH}$ the relative humidity and $\mathrm{V}$ the wind velocity. For $\mathrm{RH}=53 \%$, $\mathrm{T}_{\mathrm{c}}=22.7^{\circ} \mathrm{C}, \mathrm{T}_{\mathrm{a}}=21^{\circ} \mathrm{C}$ and $\mathrm{V}=27 \mathrm{~km} / \mathrm{h}$, Uno's prediction tool gives an evaporation rate of $0.86 \mathrm{~kg} / \mathrm{m}^{2} /$ hour. The vaporation flow of the six concretes was also measured experimentally for each test. Mass loss measurements were made using cylinders $16 \mathrm{~cm}$ in diameter and $8.2 \mathrm{~cm}$ high placed on a balance (Fig. 2). Each cylinder has an evaporation surface area of $200 \mathrm{~cm}^{2}$. The curves of evaporation as a function of time start with a linear section. The initial evaporation flow can be calculated from the slope of this linear section (Table 3). For all the tests carried out, the curves remain linear for a time lapse higher than 2.5 hours. Table 3 shows that for similar environmental conditions, initial evaporation flow seems to depend on concrete mix. Uno's tool gives a good approximation of evaporation rate. The evaporation rate of recycled coarse aggregates concrete mixes seems to be higher than that of natural aggregates concrete mixes. Initial evaporation flow seems to be weaker when effective water to cementitious material ratio decreases. Topçu et al. [22] also found that initial evaporation flow is reduced when the water to cement ratio is reduced. With wind velocity of $4.17 \mathrm{~m} / \mathrm{s}$, for $50 \%$ relative humidity and, a temperature of $28^{\circ} \mathrm{C}$, the initial evaporation flow decreased from $0.71 \mathrm{~kg} / \mathrm{m}^{2}$ to $0.59 \mathrm{~kg} / \mathrm{m}^{2}$ while w/c ratio varied from 0.59 to 0.35 .

Table 3: initial evaporation flow of the six concretes $\left(\mathrm{kg} / \mathrm{m}^{2} /\right.$ hour $)$

\begin{tabular}{ccccccc|}
\hline & $\mathrm{BR}_{0.60}$ & $\mathrm{BN}_{0.59}$ & $\mathrm{BR}_{0.52}$ & $\mathrm{GcR}_{0.45}$ & $\mathrm{GcN}_{0.45}$ & $\mathrm{GcR}_{0.38}$ \\
\hline Initial evaporation flow & 1.19 & 0.95 & 1.10 & 0.91 & 0.82 & 0.80 \\
\hline
\end{tabular}

Initial evaporation flow can be expressed in terms of the height of evaporated water per hour since one kilogramme of water corresponds to $10^{-3} \mathrm{~m}^{3}$ of water: an 
evaporation flow of $1 \mathrm{~kg} / \mathrm{m}^{2} /$ hour corresponds to a height of evaporated water of $1000 \mu \mathrm{m} /$ hour.

\subsection{Capillary depression}

Table 4: results of capillary depression measurements.

\begin{tabular}{lcccccc}
\hline & $\mathrm{BR}_{0.60}$ & $\mathrm{BN}_{0.59}$ & $\mathrm{BR}_{0.52}$ & $\mathrm{GcR}_{0.45}$ & $\mathrm{GcN}_{0.45}$ & $\mathrm{GcR}_{0.38}$ \\
\hline $\begin{array}{l}\text { Age of capillary } \\
\text { depression start (hours) }\end{array}$ & 1.22 & 0.95 & 0.83 & 0.92 & 0.86 & 0.80 \\
Age of air entry (hours) & 2.25 & 1.92 & 1.92 & 2.00 & 1.92 & 1.67 \\
Air entry value (hPa) & 91 & 94 & 117 & 143 & 152 & 181 \\
\hline
\end{tabular}

Results of these measurements show that capillary depression develops well before setting (Fig. 4 and 5) in severe desiccation conditions. The age when capillary depression begins will be determined when capillary pressure at $20 \mathrm{~mm}$ from surface reaches $5 \mathrm{hPa}$. Table 4 seems to show that capillary depression starts earlier when the effective water to cementitious material ratio is weak. At the same $\mathrm{w}_{\mathrm{eff}} / \mathrm{cm}$ ratio recycled coarse aggregates delay the beginning of capillary depression. Observation of Fig. 4 and 5 shows two phases of capillary depression development. Immediately after capillary depression starts, the difference between sensor at $20 \mathrm{~mm}$ from surface and sensor at $42 \mathrm{~mm}$ from surface begins to increase. During this first phase, difference between sensor at $20 \mathrm{~mm}$ from surface and sensor at $42 \mathrm{~mm}$ from surface reaches a maximum. This maximum corresponds to the air entry value. After the air entry the second phase begins, capillary depression field is disturbed and the difference between the two sensors decreases because fresh concrete becomes an unsaturated porous medium. Menisci reach a breakthrough radius and recede from the surface into the interior of the specimen [10], [23], [24]. Recycled coarse aggregates do not seem to influence the air entry value. Air entry value is higher for civil engineering concretes than for building concretes. Slowik et al. [10] obtained an air entry value of $15 \mathrm{kPa}$ for concrete (water to cement ratio of 0.41 ). Air entry values for civil engineering concretes are in the same order of magnitude than that obtained by Slowik et al. [10].

\subsection{Settlement}

Table 5: bleeding characteristics.

\begin{tabular}{lcccccc}
\hline & $\mathrm{BR}_{0.60}$ & $\mathrm{BN}_{0.59}$ & $\mathrm{BR}_{0.52}$ & $\mathrm{GcR}_{0.45}$ & $\mathrm{GcN}_{0.45}$ & $\mathrm{GcR}_{0.38}$ \\
\hline $\begin{array}{l}\text { Initial bleeding rate } \\
(\mu \mathrm{m} / \text { hour})\end{array}$ & 1894 & 1260 & 1764 & 562 & 958 & 538 \\
$\begin{array}{l}\text { Age of concrete placing } \\
\text { (hours) }\end{array}$ & 0.28 & 0.35 & 0.45 & 0.36 & 0.46 & 0.49 \\
$\begin{array}{l}\text { Height of steady bleed } \\
\text { water at the beginning } \\
\text { of the test }(\mu \mathrm{m})\end{array}$ & 578 & 289 & 237 & 127 & 119 & 50 \\
$\begin{array}{l}\text { Bleeding capacity } \\
\text { m) }\end{array}$ & 791 & 355 & 276 & 302 & 226 & 201 \\
\hline
\end{tabular}


Immediately after concrete placement settlement starts. Tests start 35 minutes after water cement contact. Between concrete placement and beginning of tests some settlement takes place. In order to know the total settlement, results are interpreted as follows: the age of capillary depression start corresponds to the moment when steady bleed water at concrete surface is evaporated. Thus, at the age of capillary depression start, the height of the evaporated water curve will cross the total settlement curve which corresponds to the measured settlement cumulated with the settlement that occurs between age of concrete placing and the beginning of the test. In order to extrapolate the total settlement curve, the initial slope of measured settlement curve is supposed to be constant and equal to the initial bleeding rate between the age of concrete placing and the beginning of the test [25], [26]. This hypothesis allows us to determine the age of concrete placing knowing the settlement before the beginning of the test and the initial slope of the measured settlement (Fig. 6 and 7). The height of steady bleed water at the beginning of the test corresponds to the settlement that occurs before the beginning of the test.

Table 5 shows that the initial bleeding rate of building concrete is systematically higher than that of civil engineering concrete. The initial bleeding rate decreases with the effective water to cementitious material ratio. At the same effective water to cementitious material ratio, recycled coarse aggregates seem to increase the bleeding capacity and the initial bleeding rate. The values obtained in table 5 are of the same order of magnitude as that obtained by Josserand et al. [26]. They found that bleeding capacity changes with the initial height, for an $80 \mathrm{~mm}$ height sample bleeding capacity is $700 \mu \mathrm{m}$. Bleeding capacity is also a function of the concrete mix design as it decreases when cement content increases.

Recycled coarse aggregates seem to have different behaviors with respect to bleeding. Poon et al. [27] obtained a bleeding rate of $1724 \mu \mathrm{m} /$ hour for natural aggregates concrete compared to $2164 \mu \mathrm{m} /$ hour for recycled coarse aggregates concrete (water to cement ratio of 0.55 ). The bleeding capacity is also higher for recycled coarse aggregates concrete. Yang et al. [28] have obtained a bleeding rate of $422 \mu \mathrm{m} /$ hour for natural aggregates concrete compared to 300 and 92 $\mu \mathrm{m} /$ hour for recycled coarse aggregates concrete (water to cement ratio of 0.5 ). Bleeding capacity is higher for natural aggregates concrete.

As pointed out by many authors, the tendency of bleeding largely depends on the properties of cement, water content, and the addition of fine materials. Further investigations would be needed to understand the bleeding characteristics of concrete with recycled coarse aggregates as this behavior seems to be influenced by the transfer of water from within the aggregates to the cement paste [5], [29], [30]. Such bleeding could alter the water to cement ratio in the interfacial transition zone between recycled coarse aggregates and the cement paste, affecting the bond strength [31], [32], [33]. This study shows that in severe drying conditions, for concrete with low water to cement ratio recycled coarse aggregates seem to reduce bleeding.

The total settlement curve is the sum of consolidation and vertical shrinkage. For some concretes $\left(\mathrm{BR}_{0.60}, \mathrm{BN}_{0.59}, \mathrm{BR}_{0.52}\right.$ and $\left.\mathrm{GcN}_{0.45}\right)$, settlement ends before vertical shrinkage starts (Fig. 7). Phenomena are then decoupled. Settlement curves present a horizontal landing. These concretes are all characterised by a high initial bleeding rate. The initial bleeding rate is higher than the evaporation flow for these concretes (tables 3 and 5). For these concretes bleeding capacity corresponds to the total settlement at the horizontal landing. 
For other concretes $\left(\mathrm{GcR}_{0.45}\right.$ and $\left.\mathrm{GcR}_{0.38}\right)$ vertical shrinkage starts before consolidation ends. The two phenomena coexist together (Fig. 6). For these concretes the initial bleeding rate is lower than the evaporation flow (tables 3 and 5). Bleeding capacity will then be determined as the total settlement at the capillary depression start. This method underestimates the bleeding capacity but takes into account only consolidation deformations.

\section{SYNTHESIS AND DISCUSSION}

At the release of the mixer, fresh concrete is in a thermodynamic imbalance with the ambient environment. Drying is going to allow it to reach, very slowly, a hydric balance with the ambient environment. The extraction of water from concrete, generally called drying, is mostly interpreted through the drying kinetics. The observation of the kinetics of water evaporation in concrete subjected to a controlled drying atmosphere shows generally three periods of drying: the initial drying period, when evaporation occurs from a layer of bleed water on the top surface, the constant rate period when menisci form at the topmost surface and evaporation proceeds from these menisci; and the falling rate period, when the menisci move into the specimen [34], [35]. The boundary between phase 2 and 3 is called the air entry [10] and corresponds to the point in the drying process when the menisci fall below the surface of the specimen. In drying of cementitious materials, cracking would be expected to occur at approximately this point because the tensile stress reaches a maximum [36], [37], [38]. The objective of this work is to identify permeability coefficient and its evolution during the two first phases when concrete remains saturated.

During the first period, evaporation proceeds from a layer of bleed water, which is spread across the whole surface of the drying sample. The rate of evaporation is close to that of bulk water at the same temperature. Settlement of the solid network occurs mainly due to the gravity. The solid particles sink causing the mixture to densify and the bleed water to be transported to the surface. Bleeding (table 5) is linked to the quantity of water in the concrete mix (table 2). Between concrete placing and start of the test, bleeding occurs due to the primary consolidation of concrete. The height of steady bleed water at the beginning of the test is linked to the age of concrete placing and the initial bleeding rate (table 5). In this first phase of drying, the initial bleeding rate is homogeneous on the overall height of the sample. This initial bleeding rate $V_{I R}$ is linked to the permeability of fresh concrete by the Darcy's law [13], [25]:

$V_{I R}=K\left(\Phi_{0}\right) \cdot \Phi_{0} \cdot\left(d_{S}-1\right)$

Where $\Phi_{0}$ is the initial concrete compacity, $\mathrm{K}$ the permeability coefficient $(\mathrm{m} / \mathrm{s})$ and, $d_{s}$ the solid specific density. Ghourchian et al. [16] proposed a small strains model to calculate the permeability of fresh concrete while the sedimentation mechanism proposed by Powers [25] is based on the large strains approach. The obtained values of permeability are in the range of $10^{-7}-10^{-9} \mathrm{~m} / \mathrm{s}$, while w/c ratio varied from 0.4 to 0.6 . Increasing the porosity by increasing $\mathrm{w} / \mathrm{c}$ is more effective in increasing the permeability rather than increasing the paste content for the same values of porosity [16].

Table 6: initial permeability coefficient. 


\begin{tabular}{lcccccc}
\hline & $\mathrm{BR}_{0.60}$ & $\mathrm{BN}_{0.59}$ & $\mathrm{BR}_{0.52}$ & $\mathrm{GcR}_{0.45}$ & $\mathrm{GcN}_{0.45}$ & $\mathrm{GcR}_{0.38}$ \\
\hline Initial compacity & 0.807 & 0.823 & 0.818 & 0.820 & 0.835 & 0.834 \\
Solid specific density & 2.476 & 2.688 & 2.476 & 2.492 & 2.692 & 2.492 \\
$\begin{array}{l}\text { Initial permeability } \\
\text { coefficient (m/s) }\end{array}$ & $4.5 \mathrm{E}-07$ & $2.6 \mathrm{E}-07$ & $4.1 \mathrm{E}-07$ & $1.3 \mathrm{E}-07$ & $1.9 \mathrm{E}-07$ & $1.2 \mathrm{E}-07$ \\
\hline
\end{tabular}

Initial permeability coefficient is higher for building concretes than for civil engineering concretes. Results obtained for the initial permeability coefficient follow the same trend as that obtained on the initial bleeding rate: for building concretes, incorporation of recycled aggregates seems to increase the initial permeability coefficient whatever the water to cement ratio. For civil engineering concretes, incorporation of recycled aggregates seems to decrease the initial permeability coefficient. At same cement content, using the falling-head method Assaad et al. [38] measured experimentally a permeability coefficient of $5.410^{-7}$ $\mathrm{m} / \mathrm{s}$ for $\mathrm{w} / \mathrm{c}=0.4$ concrete and $8.210^{-7} \mathrm{~m} / \mathrm{s}$ for $\mathrm{w} / \mathrm{c}=0.55$ concrete.

If evaporation occurs faster than the rate of bleeding or once the layer of bleed water at the surface is consumed by evaporation, air-liquid menisci are formed in the liquid between the solid particles on the surface. The transition between these two first phases may not be clearly identified for the drying of concrete because the bulk stiffness of fresh concrete is very high. The height of steady bleed water at the beginning of the test will influence the timing of initial capillary depression because water at the surface must be consumed by evaporation in order capillary depression starts to develop (tables 4 and 5). These menisci cause tensile stress to develop in the pore fluid. The capillary pressure produced by the menisci on the surface consolidates the concrete's solid skeleton as the tension in the fluid serves to bring the solid particles closer to each other. During this second phase, the volume of evaporated water must be immediately occupied by the solid phase to maintain a constant mass flow on the surface. To insure a constant mass flow at the surface, the water pressure has to decrease, which leads to the development of the capillary depression gradients. As a result, the pore fluid is brought to the surface of concrete and permeability coefficient decreases (Fig. 8 and 9). The values of the capillary depression or the water pressure are thus directly connected to the capacity of fresh concrete to deform, which means that they depend on the mechanical parameters of the humid granular medium (Fig. 4 and 5). On the other hand, the gradients of water pressure or capillary depression as well as their evolutions have no strong connection with the deformation of the medium, they are rather connected to the ease with which water can pass through the medium, that is, with the permeability of fresh concrete [11], [12].

For the four concretes $\mathrm{BR}_{0,60}, \mathrm{BN}_{0,59}, \mathrm{BR}_{0,52}$ and $\mathrm{GcN}_{0,45}$ the end of bleeding occurs before capillary depression begins. This means that at the end of bleeding, a thin water film covers the concrete surface for these four concretes. This is due to a high initial bleeding rate with respect to the bleeding capacity. For these four concretes identification of permeability coefficient starting from the capillary depression gradient will be possible as soon as capillary depression begins.

For the two concrete, $\mathrm{GcR}_{0,45}$ and $\mathrm{GcR}_{0,38}$ the end of bleeding occurs after capillary depression begins. This means that as soon as capillary depression starts, shrinkage and consolidation develop together for these two concretes. This is due to a low initial bleeding rate with respect to the bleeding capacity. For these two concretes, identification of permeability coefficient starting from the capillary depression gradient will be possible only after the end of bleeding. 
During this second period at constant evaporation flow, drying caused by the outside atmosphere characteristics results in liquid water transport up to the drying surface, modeled by the generalized Darcy relation [40]:

$J_{w}=\frac{K}{\rho_{w} g} \cdot \nabla p_{c}$

Where $J_{w}(\mathrm{~m} / \mathrm{s})$ is the flux of pore water to the surface, $K(\mathrm{~m} / \mathrm{s})$ is the permeability coefficient of the solid skeleton, $\rho_{\mathrm{w}}\left(\mathrm{kg} / \mathrm{m}^{3}\right)$ is the water specific mass, $\mathrm{g}\left(\mathrm{m} / \mathrm{s}^{2}\right)$ is the acceleration of gravity, $\nabla \mathrm{p}_{\mathrm{c}}(\mathrm{Pa} / \mathrm{m})$ is the capillary depression gradient at the surface. The permeability of the network gradually decreases as the network is drained and consolidated under the capillary depression (Fig 8 and 9). During this phase, the drying rate depends only on external conditions. Indeed, the transfer resistance during this period is exclusively confined in a limit layer on the humid concrete. The nature and the internal structure of concrete do not influence drying. As evaporation progresses, the pore water is drawn by capillary depression to the surface of the concrete. The radius of the liquid-air menisci decreases, which causes a higher capillary stress which further consolidates the solid. Under the increasing pressure, the network of the solid particles becomes progressively stiffer and the slope of the settlement curve decreases accordingly (Fig. 6 and 7). Because the bulk stiffness of fresh concrete is very high, the second phase of drying if very short. When a critical point is reached, the settlement of concrete stops, because capillary depression is no longer able to compress the solid skeleton of concrete and force water to the surface. At this point, the menisci reach a breakthrough radius and recede from the surface into the interior of the specimen. This minimum radius corresponds to the air entry value [10], [23]. Fig. 10 shows that the air entry value is highly dependent on effective water to cementitious material ratio. Recycled coarse aggregates don't seem to influence the air entry value as the air entry value is a physical characteristic of the paste.

After the air entry value, the field of capillary depressions is disturbed by the air entry and the identification of permeability coefficient from the capillary depression gradient is no longer possible (Fig. 8 and 9). After the air entry fresh concrete becomes an unsaturated porous media. The diamond points on Fig. 8 and 9 correspond to the initial permeability coefficient.

Table 7: permeability coefficient at air entry.

\begin{tabular}{lcccccc}
\hline & $\mathrm{BR}_{0,60}$ & $\mathrm{BN}_{0,59}$ & $\mathrm{BR}_{0,52}$ & $\mathrm{GcR}_{0,45}$ & $\mathrm{GcN}_{0,45}$ & $\mathrm{GcR}_{0,38}$ \\
\hline $\begin{array}{l}\text { Permeability } \\
\text { coefficient at air entry } \\
(\mathrm{m} / \mathrm{s})\end{array}$ & $7.5 \mathrm{E}-08$ & $3.9 \mathrm{E}-08$ & $5.2 \mathrm{E}-08$ & $2.4 \mathrm{E}-08$ & $1.8 \mathrm{E}-08$ & $8.8 \mathrm{E}-09$ \\
\hline
\end{tabular}

Results obtained on the permeability coefficient at air entry show that incorporation of recycled coarse aggregates seems to increase the permeability coefficient whatever the water to cement ratio. This increase of permeability coefficient with the use of recycled coarse aggregates is all the more important as the effective water to cementitious material ratio is higher (Fig. 11). For civil engineering concretes, incorporation of recycled aggregates seems to have a weaker influence on permeability coefficient at air entry regardless of water to cement ratio. Comparison between table 7 and table 6 shows that between the start of the test and the air entry, the permeability coefficient values fall of more than $80 \%$ for all concretes. The permeability of fresh cement paste clearly increases 
with water to cement ratio. After consolidation ended, using a common soil permeameter cell, Picandet et al. obtained a permeability of $0.3210^{-7} \mathrm{~m} / \mathrm{s}$ for an initial water to cement ratio of 0.3 and $1.8810^{-7} \mathrm{~m} / \mathrm{s}$ for an initial water to cement ratio of 0.4 [14]. These values are higher than those obtained in table 7. An 81 minutes gap between the two measures may explain these differences. Values obtained by Picandet et al. are closer to the initial permeability coefficients obtained for civil engineering concretes (table 6).

\section{CONCLUSION}

The study presented in this paper focuses on the permeability of fresh concrete under severe drying conditions and the influence of the use of recycled coarse aggregates. A new method to determine the air entry value, starting from capillary pressure gradient measurements, has been presented.

Concrete mixtures were designed varying the water-to-binder ratio and the proportion of recycled coarse aggregates. Based on the results presented in this paper the flowing conclusions can be drawn:

- The evaporation rates of concretes are around $1 \mathrm{~kg} / \mathrm{m}^{2} \cdot \mathrm{h}^{-1}$ under severe drying conditions. Concrete made of recycled coarse aggregates show significantly higher evaporation rates. At the same water to cementitious material ratio, this increase is $25 \%$ for building concretes and $11 \%$ for civil engineering concretes. This suggests that recycled coarse aggregates are able to provide initially absorbed water.

- The use of recycled coarse aggregates in concrete increases the bleeding capacity of concrete. At the same water to cementitious material ratio, this increase is $222 \%$ for building concretes and $34 \%$ for civil engineering concretes. This also suggests that recycled coarse aggregates are able to provide initially absorbed water.

- The use of recycled coarse aggregates in concrete with high water to cement ratio may lead to significant bleeding. This is consistent with previously published results. Initial permeability coefficient is higher for recycled coarse aggregates than for natural aggregates. At high evaporation rates recycled coarse aggregates are progressively dried and they contribute to evaporation because of their old paste content.

- The air entry value is not influenced by the use of recycled coarse aggregates, rather it is dependent on the effective water to cementitious material ratio.

- The use of recycled coarse aggregates increases the permeability coefficient at air entry. This increase is more important for mixtures with high water to cement ratio $(+92 \%$ for building concretes, $+33 \%$ for civil engineering concretes).

From the experimental analyses performed in this study, it seems possible to design concrete mixtures with recycled concrete coarse aggregates. Recycled coarse aggregates are likely to favor bleeding in high water to cement ratio concrete. However in severe drying conditions, for concrete with low water to cement ratio recycled coarse aggregates seem to reduce bleeding.

Permeability coefficient seems to be a very interesting physical parameter to describe water transfers in fresh concrete. Further investigations would be needed to understand the bleeding characteristics of concrete with recycled coarse aggregates as this behavior seems to be influenced by the transfer of water from within the aggregates to the cement paste. Owing to the low accuracy of 
permeability measurement, permeability coefficient at air entry was identified indirectly, starting from the Darcy's law. Water from within the aggregates to the cement paste could alter the water to cement ratio in the interfacial transition zone between recycled coarse aggregates and the cement paste, affecting the bond strength.

\section{Acknowledgments}

The authors want to thank the French National Project RECYBETON for the support of this study.

\section{REFERENCES}

[1] Bentz, D.P. A review of early-age properties of cement-based materials, Cement and Concrete Research 38 (2008) 196-204.

[2] Powers, T.C. Bleeding of Portland cement paste, mortar and concrete treated as a special case of sedimentation, Research Laboratory of Portland Cement Association bulletin 2 (1939) $160 \mathrm{pp}$.

[3] Almusallam, A.A., Maslehuddin, M., Abolu-Woris, M., Dakhil, F.H., Al-Amoudi, O.S.B. Plastic shrinkage cracking of blended cement concretes in hot environments. Mag. Concr. Res. (1999) 241-246.

[4] Gomes, M., Brito, J., \& Bravo, M. Structural concrete with incorporation of coarse recycled concrete and ceramic aggregates: durability performance. Materials and Structures, 42 (2009) 663-675.

[5] Poon, C.S., Shui, Z.H., Lam, L., Fok, H., Kou, S.C. Influence of moisture states of natural and recycled aggregates on the properties of fresh and hardened concrete. Cement and Concretes Research 34 (2004) 31-36.

[6] Wittmann, F.H. On the action of capillary pressure in fresh concrete. Cement and Concrete Research 6 (1976) 49-56.

[7] Radocea, A., A model of plastic shrinkage. Magazine of Concrete Research 46 (1994) 125-132.

[8] Cohen Menashi, D., Olek, J., Dolch, W.L. Mechanism of plastic shrinkage cracking in Portland cement and Portland cement-silica fume paste and mortar. Cement Concrete Research 20 (1990) 103-119.

[9] Hammer, T.A. Effect of silica fume on the plastic shrinkage and pore water pressure of high-strength concretes. Materials and structures 34 (2001) 273-278.

[10] Slowick, V., Schmidt, M., Fritzsch, R. Capillary pressure in fresh cement-based materials and identification of the air entry value, Cement and Concrete composites 30 (2008) 557-565.

[11] Aregba, W., Jomaa, W., Puiggali, J.R. Une approche du séchage de matériaux fortement déformables. Revue de Physique Appliquée 25 (1990) 1161-1175.

[12] Cáceres Salazar, G.E. Modélisation du séchage d'un milieu poreux saturé déformable : prise en compte de la pression du fluide. Thèse de Doctorat, Ecole Nationale d'Arts et Métiers centre de Bordeaux (2006).

[13] Josserand, L. Ressuage des bétons hydrauliques, Thèse de Doctorat, Ecole Nationale des Ponts et Chaussées (2002).

[14] Picandet, V., Rangeard, D., Perrot, A., Lecompte, T. Permeability measurement of fresh cement paste, Cement and Concrete Research 41 (2011) 330-338.

[15] Yim H.J., Kim J.H., Kwak H.G., experimental simulation of bleeding under a high concrete column, Cement and Concrete Research (57) (2014) 61-69.

[16] Ghourchian S., Wyrzykowski M., Lura P., The bleeding test: A simple method for obtaining the permeability and bulk modulus of fresh concrete, Cement and Concrete Research (89) (2016) 249-256.

[17] Salgues M., Souche J.-C., Devillers P., Garcia-Diaz E., Influence of initial saturation degree of recycled aggregates on fresh cement paste characteristics: consequences on 
recycled concrete properties, European Journal of Environmental and Civil Engineering, DOI: 10.1080/19648189.2016.1245630.

[18] Mbemba, M., Devillers, P., Adamiec, P., Loukili, A. Influence of wind on the drying of concrete at very early-age. Future Concrete, Doha, Qatar, 1-3 novembre 2010, 128139.

[19] Souche, J.C. Etude du retrait plastique des bétons à base de granulats recyclés avec mesure de l'influence du degré de saturation, Thèse de Doctorat, Université de Montpellier (2015).

[20] Turcry, P., Loukili, A. Evaluation of plastic shrinkage cracking of self- consolidating concrete. ACI Materials Journal 103 (2006) 272-279.

[21] Uno, J.P., Plastic shrinkage cracking and evaporation formulas. ACI Materials Journal 95 (1998) 365-375.

[22] Topçu I.B., Elgün V.B., Influence of concrete properties on bleeding and evaporation, Cement and Concrete Research (34) (2004) 275-281.

[23] Devillers, P., El Youssoufi, M.S. Comportement hydromécanique de sols non saturés : identification du coefficient de Biot. Proceedings of UNSATlemcen09 27-28 octobre 2009, 131-142.

[24] Slowik, V., Hübner, T., Schmidt, M. \& Villmann, B. Simulation of capillary shrinkage cracking in cement-like materials, Cement and Concrete Composites 31 (2009) 461-469.

[25] Powers, T.C. The properties of fresh concrete. John Wiley and Sons, New York (1968).

[26] Josserand, L., Coussy, O., De Larrard, F. Bleeding of concrete as an ageing consolidation process, Cement and Concrete Research 36 (9), (2006), 1603-1608.

[27] Poon, C.S., Kou, S.C., Lam, L. Influence of recycled aggregate on slump and bleeding of fresh concrete, Materials and Structures 40 (2007) 981-988.

[28] Yang, K.H., Chung, H.S., Ashour, A.F., Influence of type and replacement level of recycled aggregates on concrete properties, ACI Materials Journal, 105: 289-296.

[29] Brito, J., \& Alves, F. Concrete with recycled aggregates: the Portuguese experimental research, Materials and Structures 43 (2010) 35-51.

[30] Ferreira, L., De Brito, J., \& Barra, M. Influence of the pre-saturation of recycled coarse concrete aggregates on concrete properties,. Magazine of Concrete Research 63 (2011) 617-627.

[31] Cortas, R., Rozière, E., Staquet, S., Hamami, A., Loukili, A., Delplancke-Ogletree, M.P. Effect of the water saturation of aggregates on the shrinkage induced cracking risk of concrete at early age, Cement and Concrete Composites (50) (2014) 1-9.

[32] Nguyen, T.D., Le Saoût, G., Devillers, P., Garcia-Diaz, E. The effect of limestone aggregate porosity and saturation degree on the interfacial zone, $2^{\text {nd }}$ International Symposium on Cement-based Materials for Nuclear Wastes, Avignon, France, 3-6 juin 2014.

[33] Le T., Le-Saout G., Garcia-diaz E.,Betrancourt D., Remond S., Hardened behavior of mortar based on recycled sand - Influence of saturation state at macro-microscopic scales, Construction and Building Materials, 141 (2017) 479-490.

[34] Lura, P., Pease, B., Mazotta, G.B., Rajabipour, F., Weiss, J. Influence of shrinkagereducing admixtures on development of plastic shrinkage cracks. ACI Material Journal 104 (2007) 187-193.

[35] Scherer, G.W. Theory of drying, Journal of the American Ceramic Society 73 (1990) 3-14.

[36] Scherer, G.W. Crack-tip stress in gels, Journal of Non-Crystalline solids 144 (1992) 210-216.

[37] Holt, E., Leivo, M. Cracking risks associated with early age shrinkage, Cement and Concrete Composites 26 (2004) 521-530.

[38] Qi, C., Weiss, W.J. and Olek, J. Characterization of plastic shrinkage cracking in fiber reinforced concrete using semi-automated image analysis, Concrete Science and Engineering 36 (2003) 386-395. 
[39] Assaad J., Harb J., Use of the falling-head method to assess assess permeability of freshly mixed cementitious-based materials, Journal of Materials in Civil Engineering (25) (2012) 580-588.

[40] Coussy, O., Baroghel-Bouny, V., Dangla, P., Manguy, M. Evaluation de la perméabilité à l'eau liquide des bétons à partir de leur perte de masse durant le séchage, Revue Française de Génie Civil 5 (2001) 269-284.

\section{Figure captions}

Fig. 1 Size grading curves of all coarse aggregates.

Fig. 2 Schematic diagram of the experimental set-up of the wind tunnel.

Fig. 3 Experimental system for measuring settlement and capillary depression

Fig. 4 Capillary depression for the $\mathrm{GcR}_{0.38}$ concrete.

Fig. 5 Capillary depression for the $\mathrm{BR}_{0.60}$ concrete.

Fig. 6 Settlement for the $\mathrm{GcR}_{0.38}$ concrete.

Fig. 7 Settlement for the $\mathrm{BR}_{0.60}$ concrete.

Fig. 8 Evolution of permeability coefficient for the building concretes.

Fig. 9 Evolution of permeability coefficient for the civil engineering concretes.

Fig. 10 Air entry value versus $\mathrm{w}_{\text {eff }} / \mathrm{cm}$.

Fig. 11 Permeability coefficient at air entry versus $\mathrm{w}_{\mathrm{eff}} / \mathrm{cm}$.

Fig. 1 Size grading curves of all coarse aggregates.

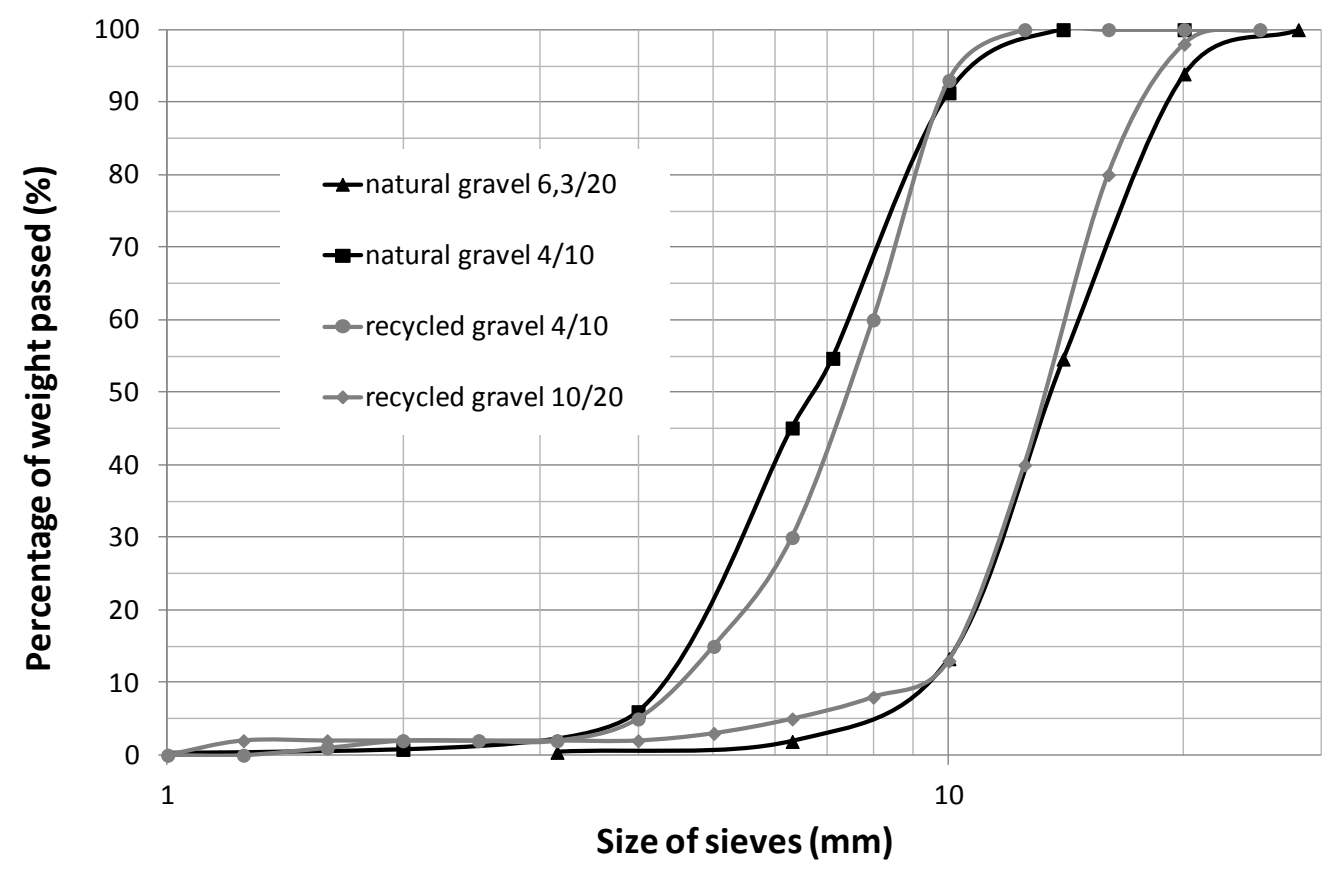

Fig. 2 Schematic diagram of the experimental set-up of the wind tunnel.

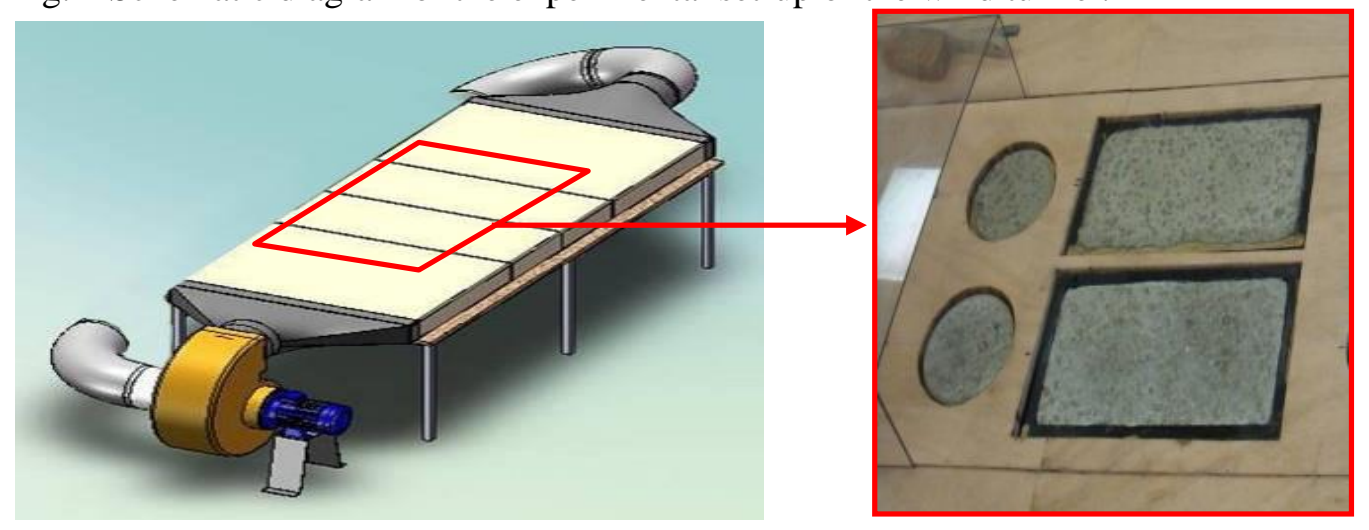


Fig. 3 Experimental system for measuring settlement and capillary depression

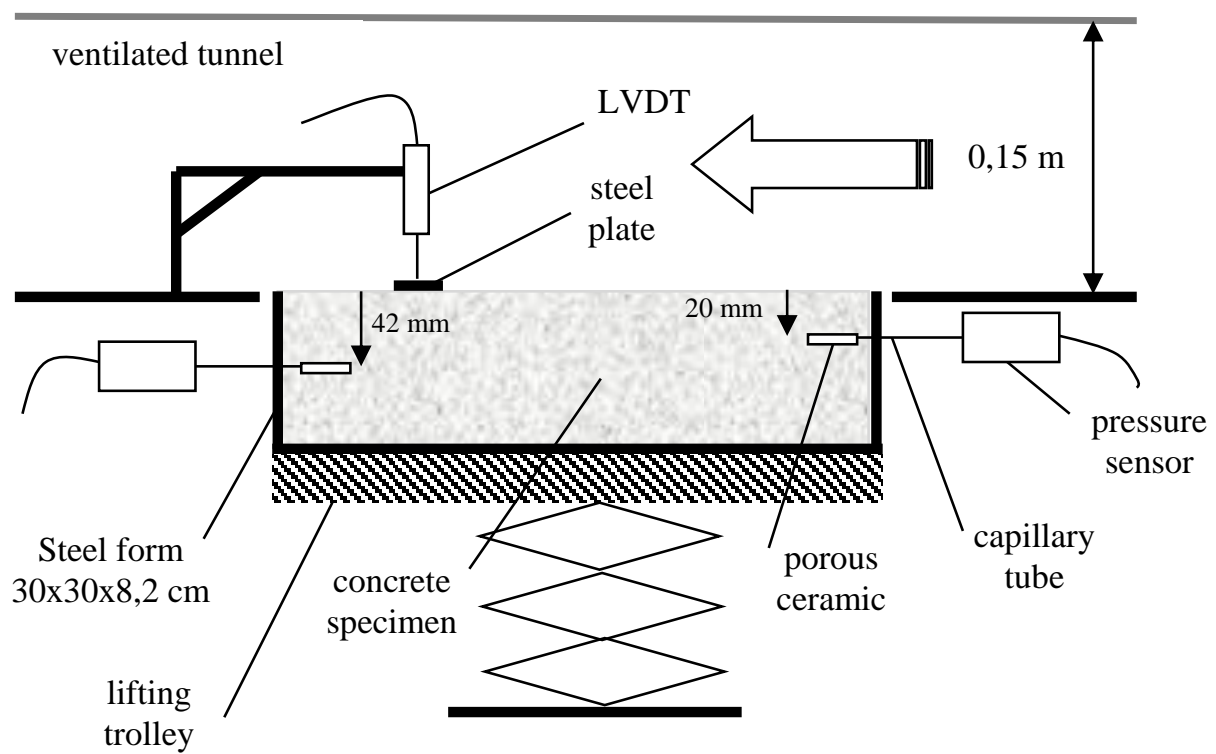

Fig. 4 Capillary depression for the $\mathrm{GcR}_{0.38}$ concrete.

Time (hours)

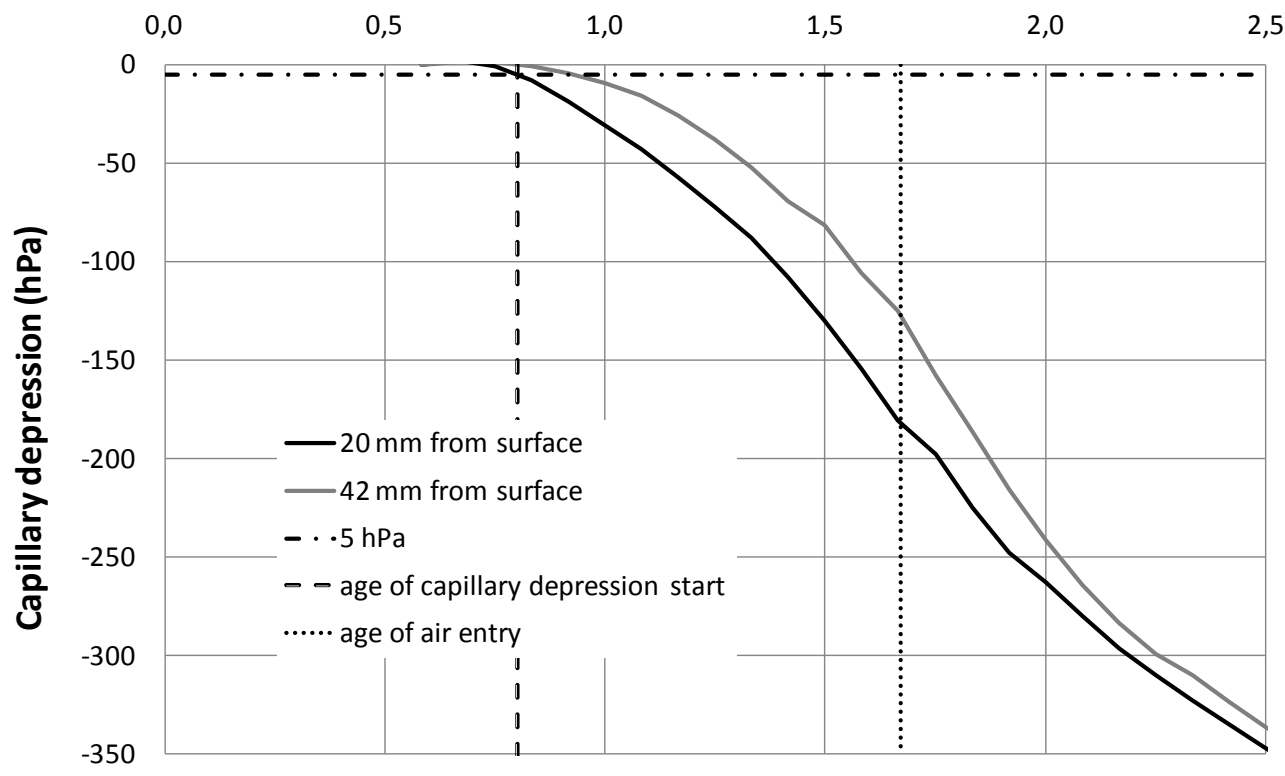


Fig. 5 Capillary depression for the $\mathrm{BR}_{0.60}$ concrete.

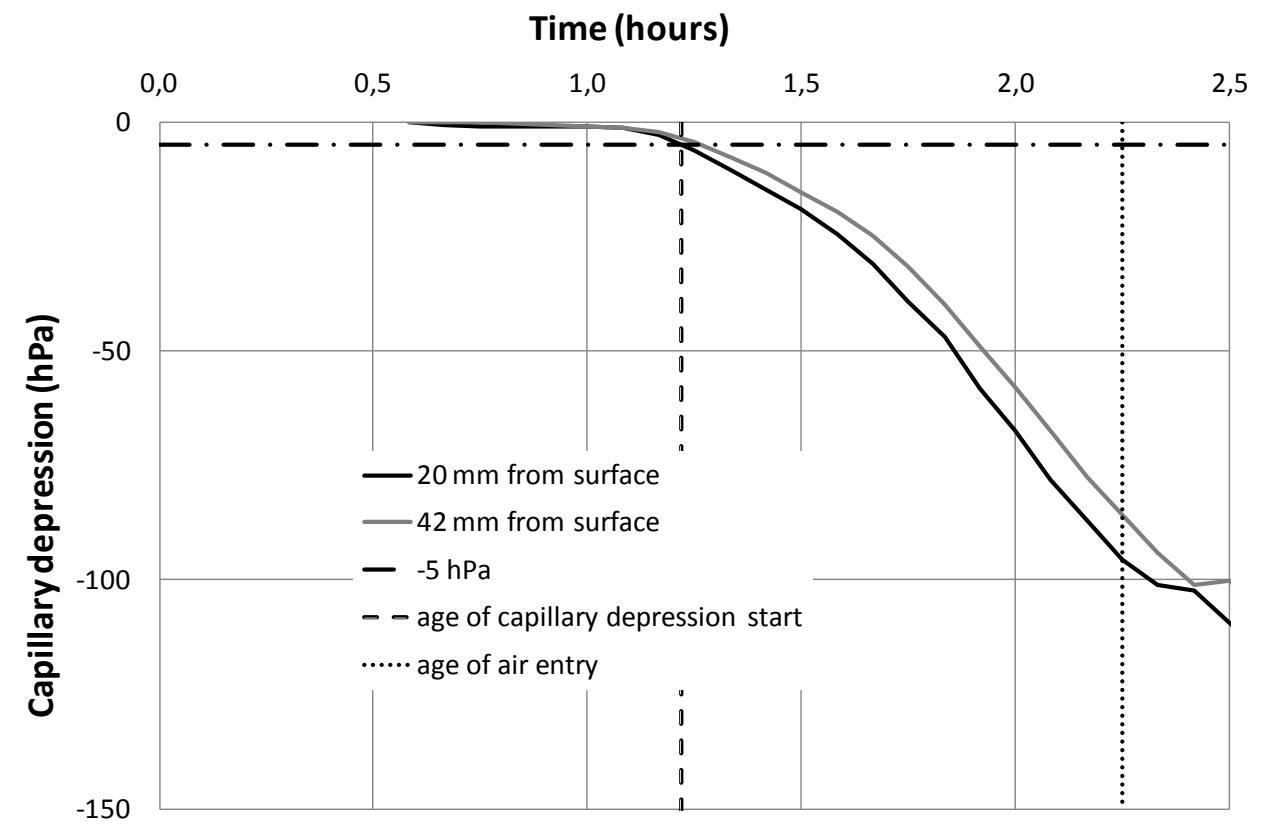

Fig. 6 Settlement for the $\mathrm{GcR}_{0.38}$ concrete.

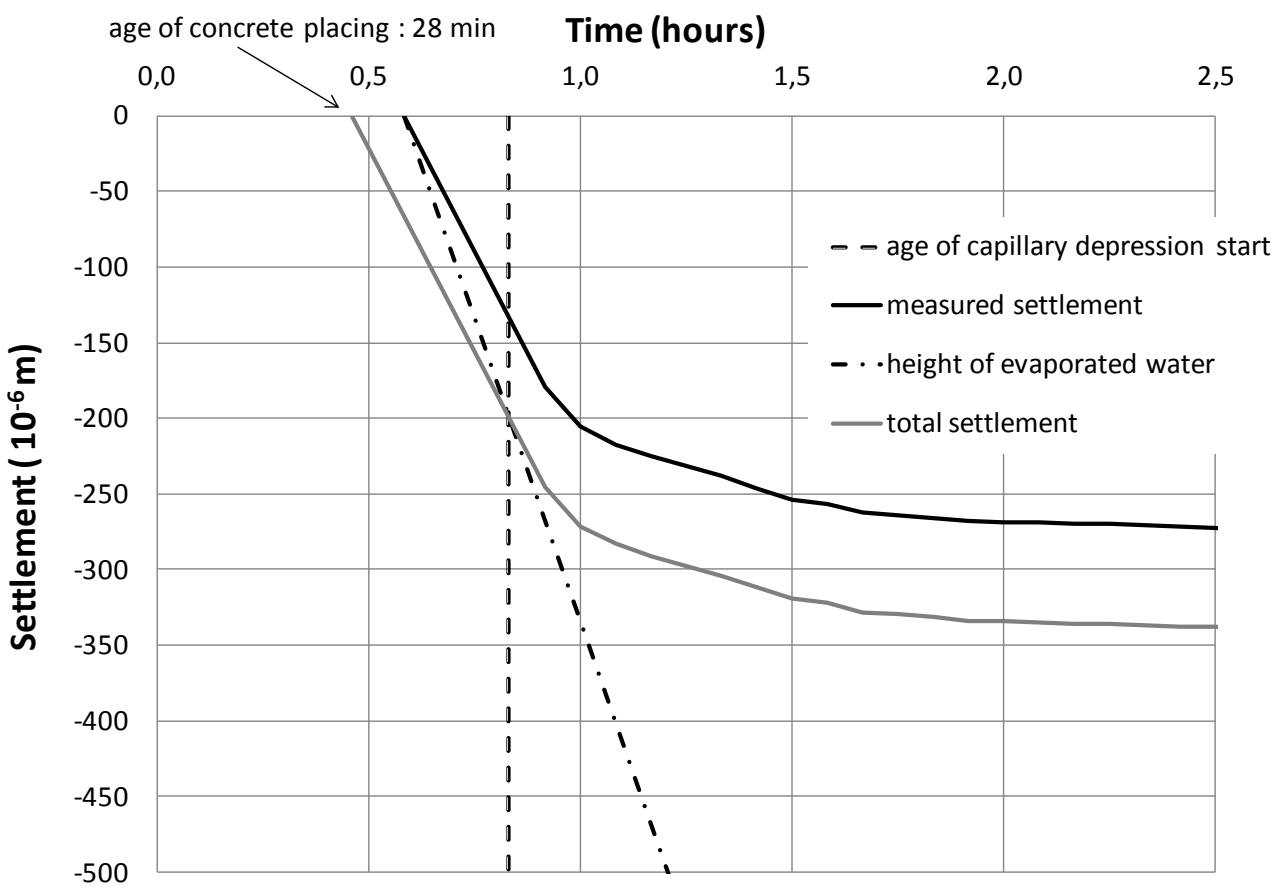


Fig. 7 Settlement for the $\mathrm{BR}_{0.60}$ concrete.

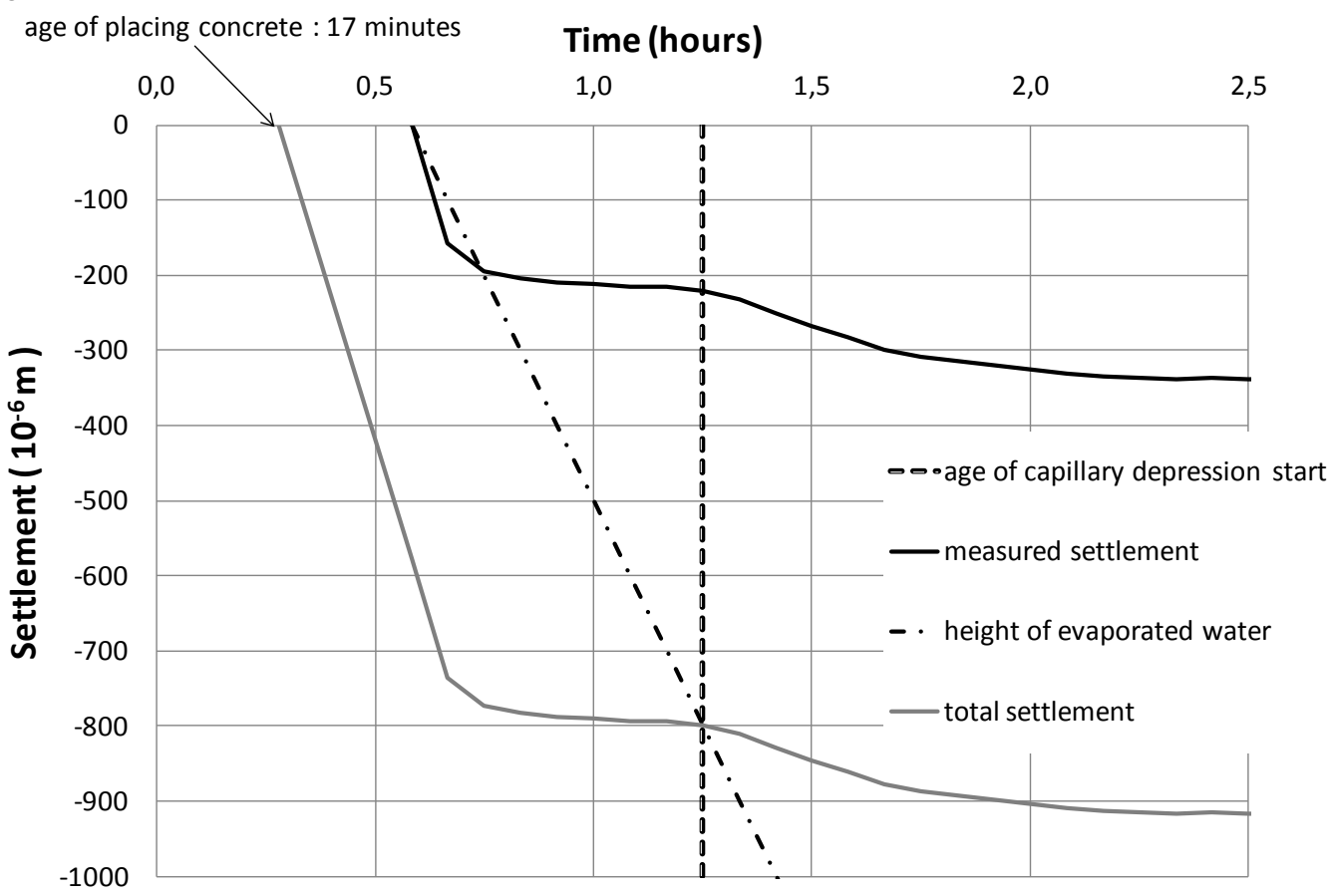

Fig. 8 Evolution of permeability coefficient for the building concretes.

\section{Time (hours)}

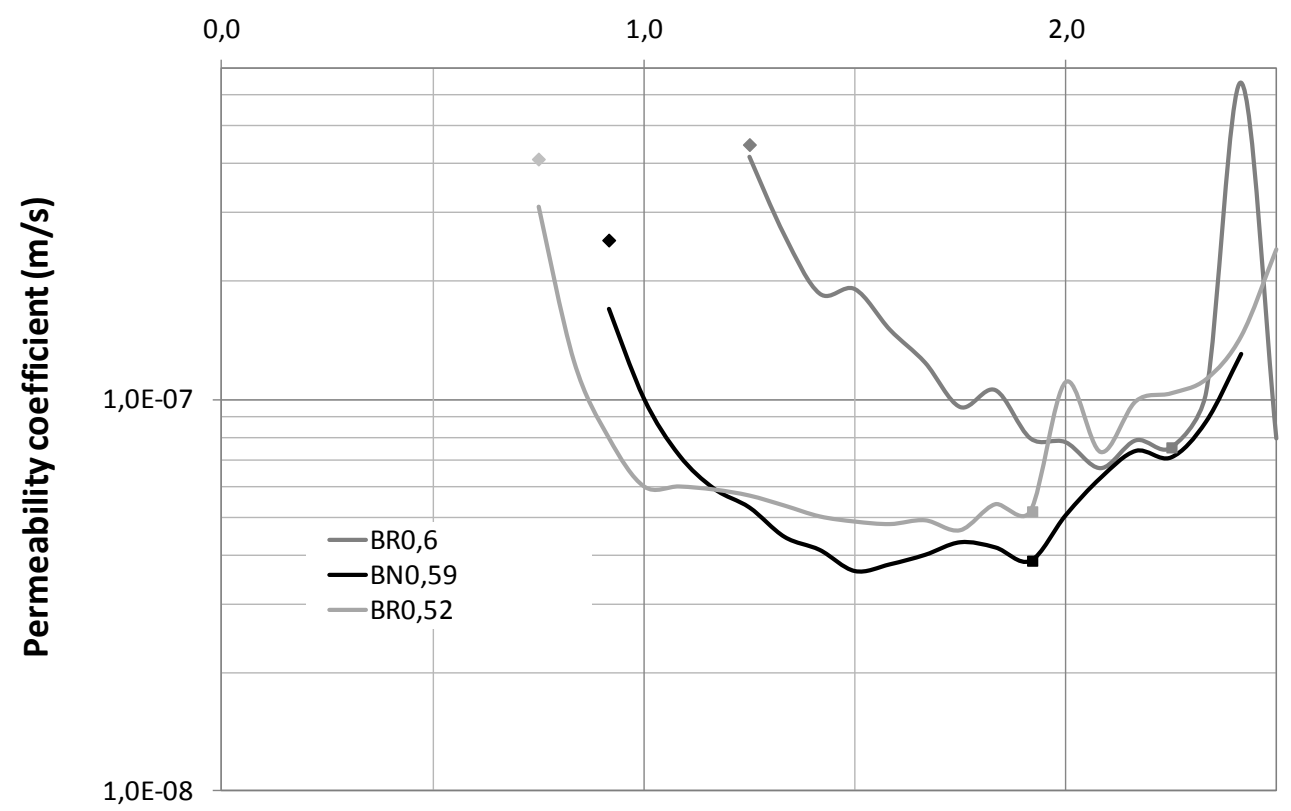


Fig. 9 Evolution of permeability coefficient for the civil engineering concretes.

\section{Time (hours)}

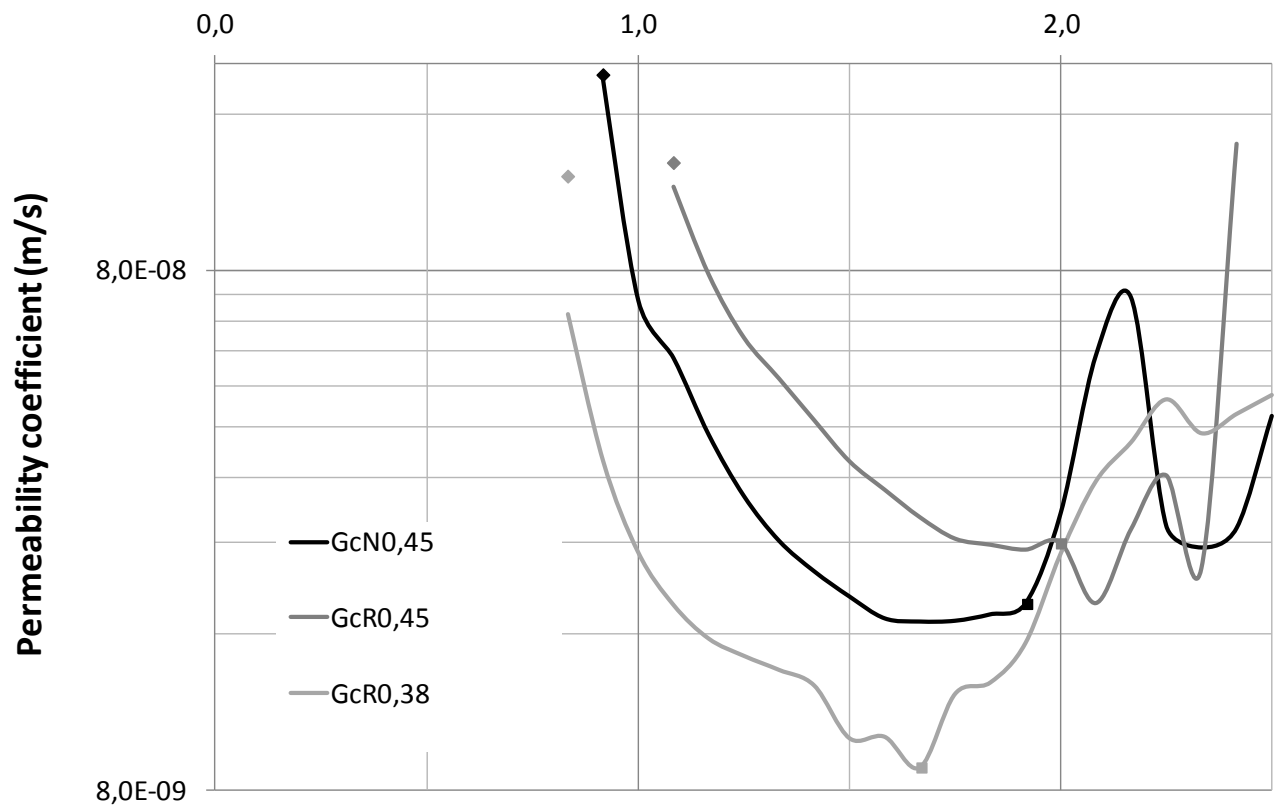

Fig. 10 Air entry value versus $\mathrm{w}_{\text {eff }} / \mathrm{cm}$.

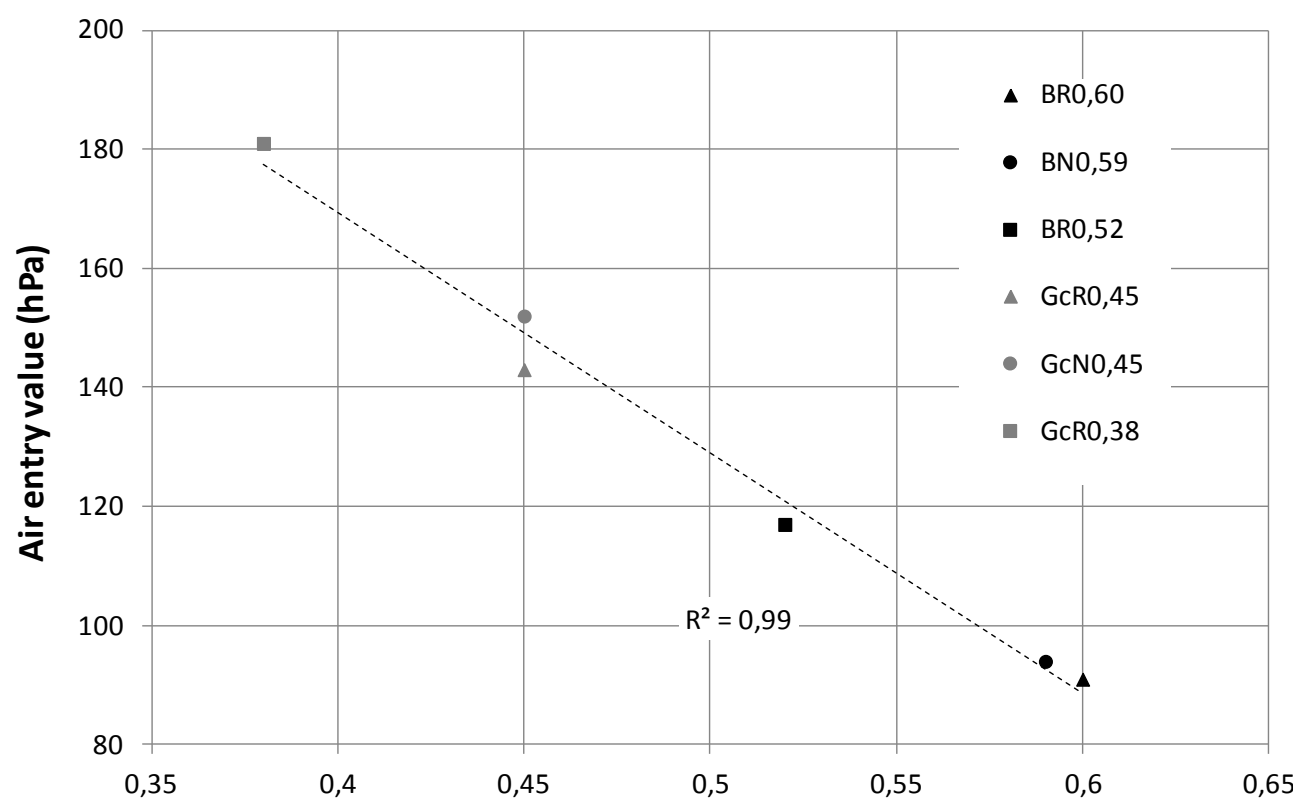

Effective water to cementitious material ratio $\left(w_{\text {eff }} / \mathrm{cm}\right)$ 
Fig. 11 Permeability coefficient at air entry versus $\mathrm{w}_{\mathrm{eff}} / \mathrm{cm}$.



